Editorial

\title{
Application of Pediatric Balance Scales in Children with Cerebral Palsy*
}

\author{
D. A. Sival ${ }^{1}$ \\ ${ }^{1}$ Department of Pediatrics, Beatrix Children's Hospital, University \\ Medical Center Groningen, University of Groningen, Groningen, \\ The Netherlands
}

Neuropediatrics 2012;43:305-306.

Human postural control involves the complex task to integrate automatic postural responses and multisensory (visual, labyrinthine, and proprioceptive) feedback for the adjustment of motor output. ${ }^{1}$ Some multisensory signals provide information for dynamic and static balance, others stabilize body segments (i.e., head, trunk, or arm) to provide a reference for the planning of movements, and finally there are signals that assist in the proper execution of movements. The temporal development of multisensory integration results in the achievement of motor milestones such as rolling, sitting, and walking. By maturation and training, postural adaption may improve until after adolescence. ${ }^{2}$ Accuracy of motor learning by visual feedback has revealed that 12 -year-old children depend less on visual information than 6 to 8-yearold children. ${ }^{3}$ But even after the 12th year of life, protracted development of visual integration may still occur until adulthood. Multisensory integration for postural control involves functional activity of the premotor and supplementary areas, basal ganglia, and cerebellum. In children with cerebral palsy $(\mathrm{CP})$, nonprogressive damage of associated brain areas and subsequent neurologic impairment (spasticity, cocontractions, muscle weakness, and visual impairment) can interfere with the development of static and dynamic balance. ${ }^{4}$

In this perspective, accurate assessment of postural control is important for children with CP. Traditionally, balance function is assessed by standardized developmental tools such as Gross Motor Function Measure (GMFM), ${ }^{5}$ by laboratory platforms, ${ }^{1,6}$ or by deduction from parental interviews (such as by standardized Pediatric Evaluation of Disability Inventory [PEDI]). However, GMFM appears more indicative for global motor function than for balance because GMFM

${ }^{*}$ This article is an editorial on "Validity of pediatric balance scales in children with spastic cerebral palsy" by Sook-Hee et al (Neuropediatrics 2012;43(6):307-313).

hardly focuses on unusual fine motor skills of the head and foot. Assessment of balance by external perturbations of platforms involves standardized laboratory simulations requiring expensive hardware. ${ }^{7}$ In children with $\mathrm{CP}$, a reliable, simple, and clinically relevant measure for balance could therefore provide a valuable assessment tool for ubiquitous application. Ideally, such a balance scale would fulfill requirements of good interobserver reliability, construct validity (i.e., should measure balance problems), convergent validity (i.e., results correlate with other test outcomes that reflect balance), and discriminant validity (i.e., results do not correlate with test outcomes that are supposed to be unrelated with balance). ${ }^{8}$

In the present edition, the interesting article "Validity of pediatric balance scales in children with spastic cerebral palsy" addresses convergent and discriminant validity of the pediatric balance scale $\left(\mathrm{PBS}^{9}\right)$ in $\mathrm{CP}$ children, aged 4 to 10 years. ${ }^{10}$ The PBS involves a simple and easily clinically applicable scale consisting of 14 items which are relevant for everyday tasks. These tasks involve items related to sitting, standing (with eyes open and closed), turning, reaching, etc. ${ }^{9}$ The results indicate a high convergent validity with GMFM dimensions of standing and walking, and a moderate convergent validity with Sensory Organization Test derived from computerized dynamic posturography (with fixed foot support and open and closed eyes) and PEDI (mobility domain). The authors report that PBS can distinguish between three different levels of GMFM impairment (varying from mild impairment of advanced skills to walking with assistive mobility). The authors attribute the latter finding to discriminant validity, although an alternative explanation cannot be excluded. Since PBS can discriminate between GMFM levels and since both tests are associated with postural control, one could decide to attribute this finding to convergent validity, instead. The authors recognized that the number of included

Copyright $(2012$ by Thieme Medical Publishers, Inc., 333 Seventh Avenue, New York, NY 10001, USA. Tel: +1(212) 584-4662.
DOI http://dx.doi.org/ $10.1055 / \mathrm{s}-0032-1329611$. ISSN 0174-304X.

reprint requests D. A. Sival, MD,
PhD, Department of Pediatrics,

Beatrix Children's Hospital,

University Medical Center

Groningen, University of

Groningen, PO Box 30.001,

9700RB Groningen,

The Netherlands

(e-mail: d.a.sival@bkk.umcg.nl). 
children is small, which prohibited subgroup analysis. Since the concept of $\mathrm{CP}$ involves an umbrella covering clinically and pathologically heterogeneous subgroups, analysis according to $\mathrm{CP}$ subgroups, laterality and comorbidity seems warranted. For instance, asymmetrical postural adjustments in hemiplegic children could have a different effect on test correlations than more symmetrical postural arm movements in diplegic children. The authors reported that vision disoriented and vision occluded trials revealed weaker correlations between PBS and Sensory Organization Test (computerized dynamic posturography) than visually guided trials. Lacking subgroup analysis, it remains unclear whether comorbidity such as concentration or endurance deficits could explain this. Interestingly, present results are obtained in 4- to 10-year-old children, who are also reported to be more dependent on visual feedback than older children. ${ }^{3}$ However, due to the heterogeneity of $\mathrm{CP}$, thorough analysis according to welldescribed subgroups appears methodologically difficult. Altogether, within the limitations of the study, present results do indicate that PBS could function as a valuable and clinically useful balance test in children with spastic $\mathrm{CP}$.

Although hopeful, present data do not automatically implicate that longitudinal PBS outcomes in young CP children can be interpreted in a straight forward way. In CP children, both multisensory integration and cerebral motor areas may still develop and even disabled children can reveal new developmental skills throughout childhood. One could thus imagine that moderately improved PBS scores in young children could be mistakenly interpreted as therapeutic gain. Although CP children may reveal an earlier developmental arrest of age-related multisensory improvement (at least regarding standing balance ${ }^{4}$ ), developmental PBS data for CP subgroups are still lacking. By the age of 7 years, healthy children are generally able to perform all PBS items in a successful way. ${ }^{9}$ Until clarification of age-related PBS out- comes in CP subgroups, one might thus try to avoid therapeutic over-interpretation of longitudinal PBS trials, at least in $\mathrm{CP}$ children younger than 7 years of age.

\section{References}

1 Forssberg H, Nashner LM. Ontogenetic development of postural control in man: adaptation to altered support and visual conditions during stance. J Neurosci 1982;2(5):545-552

2 de Graaf-Peters VB, Blauw-Hospers CH, Dirks T, Bakker H, Bos AF, Hadders-Algra M. Development of postural control in typically developing children and children with cerebral palsy: possibilities for intervention? Neurosci Biobehav Rev 2007;31(8):1191-1200

3 Fayt C, Minet M, Schepens N. Children's and adults' learning of a visuomanual coordination: role of ongoing visual feedback and of spatial errors as a function of age. Percept Mot Skills 1993;77(2): $659-669$

4 Rose J, Wolff DR, Jones VK, Bloch DA, Oehlert JW, Gamble JG. Postural balance in children with cerebral palsy. Dev Med Child Neurol 2002;44(1):58-63

5 Russell DJ, Avery LM, Rosenbaum PL, Raina PS, Walter SD, Palisano RJ. Improved scaling of the gross motor function measure for children with cerebral palsy: evidence of reliability and validity. Phys Ther 2000;80(9):873-885

6 Brogren E, Hadders-Algra M, Forssberg H. Postural control in sitting children with cerebral palsy. Neurosci Biobehav Rev 1998;22(4):591-596

7 Westcott SL, Lowes LP, Richardson PK. Evaluation of postural stability in children: current theories and assessment tools. Phys Ther 1997;77(6):629-645

8 Campbell DT, Fiske DW. Convergent and discriminant validation by the multitrait-multimethod matrix. Psychol Bull 1959;56(2): 81-105

9 Franjoine MR, Darr N, Held SL, Kott K, Young BL. The performance of children developing typically on the pediatric balance scale. Pediatr Phys Ther 2010;22(4):350-359

10 Sook-Hee Y, Ji Hye H, Sang-Joon K, Jeong-Yi K. Validity of pediatric balance scales in children with spastic cerebral palsy. Neuropediatrics 2012;43(6):307-313 